\title{
A INTEGRIDADE DO DIREITO E O DEVER DE O MINISTÉRIO PÚBLICO PROCESSAR DIRETAMENTE O AGENTE PÚBLICO: O CASO DOS DANOS MORAIS COLETIVOS PRATICADOS PELO MINISTRO DA EDUCAÇÃO
}

LAW'S INTEGRITY AND THE DUTY OF THE FEDERAL PROSECUTION OFFICE IN DIRECTLY CHARGING THE RESPONSIBLE OFFICIAL - A CASE STUDY CONCERNING MORAL DAMAGES COMMITTED BY BRAZIL'S MINISTER OF EDUCATION

\section{Emanuel de Melo FerReira*}

\section{RESUMO}

O presente artigo busca responder à seguinte pergunta: a Constituição autoriza que o Ministério Público ajuíze ação de reparação de danos diretamente contra determinado agente público? A questão, aparentemente simples e já amplamente debatida na doutrina de direito administrativo e na jurisprudência dos tribunais, é explorada no presente texto de modo não usual, pois: a) limita a interpretação da responsabilização objetiva do Estado, prevista no art. $37, \S 60$ da Constituição, às hipóteses em que o Ministério Público, e não o particular, ajuízam a ação; b) analisa tal dispositivo em contexto com o art. 129, III também da Constituição, o qual prevê como dever fundamental do Ministério Público a proteção ao patrimônio público, necessariamente desfalcado caso a ação seja proposta contra a pessoa jurídica respectiva. Conclui, a partir da teoria dos precedentes de Ronald Dworkin e de Juraci Mourão, que a tese da "dupla garantia" prevista no RE 327.904 é inaplicável ao caso.

Palavras-chave: Ministro da Educação; Teoria dos precedentes; Responsabilização pessoal.

\section{ABSTRACT}

This paper aims to answer the following question: does the Constitution allows that the Federal Prosecution Office charges directly an official that, for instance has committed moral damages against professors and students in brazilian universities? To answer that question, the interpretation of articles $37, \S 60$ and 129, III takes place in the context of the precedents concerning the case, especially the extraordinary appeal no 327.904, judged by Brazilian Supreme Court. In that case, the Court had not allowed the direct responsibility of the public agent, but the theory of precedents developed by Ronaldo Dworkin or Juraci Mourão help to justify the distinguishing or even the overruling in the case.

Keywords: moral damages; Minister of Education; theory of precedents; personal responsibility.

* Doutorando, Mestre e Graduado em Direito pela Universidade Federal do Ceará (UFC).

Professor Assistente I da Universidade do Estado do Rio Grande do Norte (UERN). Procurador da República. emanueldemelo@msn.com 


\section{SUMÁRIO}

\section{INTRODUÇÃO; 1 ESTUDANDO O CASO SEM RESUMIR O DIREITO ÀS DECISÕES JUDICIAIS; 2 A INTEGRIDADE DO DIREITO - SUPERAÇÃO E DISTINÇÃO DE PRECEDENTES EQUIVOCADOS; CONCLUSÕES; REFERÊNCIAS.}

\section{- INTRODUÇÃO}

O presente artigo busca responder à seguinte pergunta: a Constituição autoriza que o Ministério Público ajuíze ação de reparação de danos diretamente contra determinado agente público? A questão, aparentemente simples e já amplamente debatida na doutrina de direito administrativo e na jurisprudência dos tribunais, é explorada no presente texto de modo não usual, pois: a) limita a interpretação da responsabilização objetiva do Estado, prevista no art. 37, §60 da Constituição, às hipóteses em que o Ministério Público, e não o particular, ajuízam a ação; b) analisa tal dispositivo em contexto com o art. 129, III também da Constituição, o qual prevê como dever fundamental do Ministério Público a proteção ao patrimônio público, necessariamente desfalcado caso a ação seja proposta contra a pessoa jurídica respectiva.

A abordagem ora proposta, ainda, é atual porque parte de estudo de caso relacionado à ação civil pública número 0800928-89.2019.4.05.8401¹, na qual o Ministério Público Federal em Mossoró pleiteou a condenação direta do Ministro da Educação, Abraham Weintraub, em face de danos morais coletivos à honra e à imagem de estudantes e professores das universidades federais, ambientes classificados como locais de "balbúrdia". A escolha da metodologia do estudo de caso justifica-se, para além do didatismo que tal estudo proporciona aos alunos iniciantes no estudo do direito, na necessidade de se analisar diversos precedentes judiciais relacionados ao tema objeto de investigação neste artigo, o qual, assim, mostra-se voltado para pesquisa em torno da teoria dos precedentes.

Sendo assim, o texto recorrerá a dois referenciais para se alcançar a resposta adequada à questão lançada. Inicialmente, o direito como integridade de Ronald Dworkin será analisado na exata medida em que se sustenta a necessidade de se abandonar um precedente equivocado, não sendo suficiente a mera coerência ou a aplicação automática de um caso anterior ao futuro. Dando continuidade às ideias de tal autor, Juraci Mourão, no Brasil, destaca-se com uma teoria dos precedentes voltada para a análise da força hermenêutica deles, contribuindo para analisar, por exemplo, se o precedente firmado pelo Supremo Tribunal Federal (STF) no Recurso Extraordinário (RE) no 327.904², o qual consagra a tese da "dupla garantia", apresentaria força capaz de afastar a responsabilização direta do agente público.

Percebe-se, assim, como o tema é atual e relevante, proporcionando um estudo entre o Direito Constitucional, a Filosofia e a Sociologia do Direito, especialmente quando se analisa a questão sob o aspecto da máxima eficácia das normas constitucionais. Nesse sentido, poderse-ia formular a seguinte hipótese de trabalho: caso seja admita a tese da responsabilização

\footnotetext{
${ }^{1} 10$ a Vara Federal da Subseção Judiciária de Mossoró.

${ }^{2}$ Relator Ministro Carlos Britto.
} 
A integridade do Direito e o dever de o Ministério Público processar diretamente o agente público: o caso dos danos morais coletivos praticados pelo Ministro da Educação

direta, haveria uma maior eficácia da Constituição, com a reparação do dano, por exemplo, sem a necessidade de processamento de precatórios, procedimento necessário caso a pessoa jurídica fosse demandada e, ao final condenada. A questão merece ser cuidadosamente analisada e posta à prova.

\section{ESTUDANDO O CASO SEM RESUMIR O DIREITO ÀS DECISÕES JUDICIAIS}

O estudo de caso foi desenvolvido nos Estados Unidos a partir das aulas de Christopher Columbus Langdell, o qual sustentava que somente a partir da análise das decisões dos tribunais, o aluno poderia compreender o que realmente o Direito era. ${ }^{3} \mathrm{O}$ estudo de caso tem a vantagem de trazer aspectos práticos para a sala de aula, não se confundindo, por outro lado, como os meros exemplos citados pelo professor como forma de ilustrar sua explanação. Tem também inegável cunho histórico, ao possibilitar o entendimento acerca das razões que levaram à tomada de determinada decisão. Os alunos, ao lerem um acórdão e os respectivos votos, podem se sentir instigados na análise do raciocínio judicial e das divergências de fundamentos, até mesmo, entre os juízes que concluíram o caso de modo igual.

Por outro lado, a adoção única de tal método passa a impressão equivocada de que o Direito é aquilo que os tribunais dizem ${ }^{4}$, numa postura realista que demonstra profundo ceticismo em relação à norma jurídica. Hart aponta como a posição realista desconfia das normas jurídicas e do papel delas como padrões que, efetivamente, informem a atividade judicial:

O ceticismo em relação às normas merece realmente nossa atenção, mas apenas como uma teoria sobre a função das normas na decisão judicial. Assim, mesmo que admitamos todas as objeções para as quais chamamos a atenção, a teoria se reduz à tese de que, no que diz respeito aos tribunais, nada existe que limite a área de textura aberta, de modo que é falso, senão insensato, considerar que os próprios juízes são sujeitos a normas ou "obrigados" a decidir as causas como o fazem. Eles podem até atuar como uniformidade e regularidade suficientemente previsíveis, para permitir que os outros vivam, durante longos períodos, de acordo com as decisões dos tribunais, considerando-as como normas. Podem até sentir certa compulsão para tomar as decisões que tomam, e esses sentimentos também podem ser previsíveis; mas, fora isso, nada existe passível de ser caracterizado como uma norma que devam seguir. Não há nada que os tribunais tratem como padrões de procedimento judicial correto, e, portanto, nada há nesse comportamento que manifeste o ponto de vista interno típico da aceitação de normas. ${ }^{5}$

Tal postura não pode ser admitida num Estado Democrático de Direito que promove a separação entre o Poder Judiciário e Legislativo, já que converte juízes em legisladores. Além

\footnotetext{
${ }^{3}$ RAMOS, Luaciana de Oliveira. SCHORSCHER, Vivian Cristina. Método do caso. In.: In.: Métodos de ensino em Direito - conceitos para um debate. GHIRARDI, José Garcez (org.). São Paulo: Saraiva, 2009. p, 49.

${ }^{4}$ GHIRARDI, José Garcez. Ob. cit. p, 77.

${ }^{5}$ HART, H.L.A. O conceito de Direito. Trad. de Antônio de Oliveira Sette-Câmara. São Paulo: Martins Fontes, 2012. p, 179.
} 
disso, se o Direito é o que os tribunais assim dizem, não haveria como explicar o papel das normas que criam tais instituições ${ }^{6}$.

No caso em estudo, a ação civil pública ajuizada buscava a condenação do Excelentíssimo Senhor Ministro da Educação por danos morais coletivos causados aos alunos e professores das instituições públicas de ensino superior em face de reiteradas condutas por ele praticadas desde que assumiu a respectiva pasta:

I) declaração proferida em entrevista concedida ao Estado no dia 30/04/2019, apontando que "Universidades que, em vez de procurar melhorar o desempenho acadêmico, estiverem fazendo balbúrdia, terão verbas reduzidas"7 As declarações, diga-se desde já, demonstram clara vontade discriminatória por parte do réu, pois as universidades inicialmente retaliadas pelo MEC (UFF, UFBA e UnB) atingiram ótimo desempenho, conforme se depreende da análise do sítio eletrônico do Times Higher Education, um dos principais rankings de avaliação do ensino superior ${ }^{8}$;

II) declaração proferida em 20/05/2019, quando, interpelado em reunião com Reitores e membros da bancada parlamentar do Rio Grande do Norte acerca de como restaria efetivado o serviço de limpeza na Universidade Rural Federal do SemiÁrido (UFERSA), Universidade Federal do Rio Grande do Norte (UFRN) e Institutos Federais do Rio Grande do Norte (IFRN), propôs que "se chamasse o CA e o DCE" para realização dos serviços ${ }^{9}$, em clara referência aos estudantes de tais instituições representados por tais órgãos, os quais poderiam ser concitados a prestarem serviço ilegal que não lhes cabe. A proposta parte da premissa inafastável de que, para Sua Excelência, os respectivos alunos são desocupados, não realizando a contento as atividades de ensino, pesquisa e extensão a ponto de ostentarem tempo livre para, ilegalmente, exercerem tarefa que cabe à Administração;

III) em 22/05/2019, durante a audiência na Comissão de Educação na Câmara dos Deputados, se recusou a pedir desculpas por usar o termo "balbúrdia" ao se referir as universidades federais. "Eu não tenho problema nenhum em pedir desculpas, mas esse não", disse Sua Excelência em resposta ao deputado Marcelo Freixo (PSOL) ${ }^{10}$.

A breve apresentação dos fatos, para os fins deste artigo, justifica-se, unicamente, para se ter clareza quanto à análise dos precedentes que estarão em disputa na admissão da responsabilização direta do referido agente público. Não é objeto da presente investigação,

\footnotetext{
${ }^{6} \mathrm{~A}$ seguinte passagem esclarece a crítica ao realismo: "No entanto, nesse ponto, cabe fazer uma outra pergunta: Como sabemos que são os juízes? O realismo não fornece uma resposta coerente para essa questão, permanecendo aparentemente válida a observação de Kelsen e Hart, entre outros, de que esse corrente deve pelo menos admitir a existência de normas que dão a certos indivíduos a competência para agirem como juízes, não havendo nenhuma propriedade natural que distinga os juízes dos não juízes, dependendo, sim a diferenciação de que os primeiros estejam autorizados por certas normas e outros não". NINO, Carlos Santiago. Introdução à análise do Direito. Trad. Elza Maria Gasparotto. São Paulo: Martins Fontes, 2015. p, 54.

7 Disponível em: https://educacao.estadao.com.br/noticias/geral,mec-cortara-verba-de-universidade-porbalburdia-e-ja-mira-unb-uff-e-ufba,70002809579. Acessado em: 27/05/2019.

${ }^{8}$ Disponível em: < https://g1.globo.com/ba/bahia/noticia/2019/04/30/nao-sei-o-que-motivou-o-comentariodizreitor-da-ufba-sobre-justificativas-do-ministro-da-educacao-para-cortes-em-verbas.ghtml > Acesso em: 27/05/2019.

${ }^{9}$ Conforme depoimento do Magnífico Reitor da Universidade Federal Rural do Semi-Árido, José de Arimateia, juntados aos autos.

${ }^{10}$ Disponível

em:

https://www.correiobraziliense.com.br/app/noticia/politica/2019/05/22/interna_politica,756608/ministro-daeducacao-recusa-a-se-desculpar-por-usar-o-termo-u201cbalb.shtml. Acessado em: 27/05/2019.
} 
A integridade do Direito e o dever de o Ministério Público processar diretamente o agente público: o caso dos danos morais coletivos praticados pelo Ministro da Educação

assim, se tal conduta realmente é capaz de gerar dano moral, muito embora haja forte carga argumentativa nesse sentido. Apresentados os fatos relevantes do caso, far-se-á a análise dos precedentes.

\title{
2 A INTEGRIDADE DO DIREITO - SUPERAÇÃO E DISTINÇÃO DE PRECEDENTES EQUIVOCADOS
}

\author{
Como se sabe, o artigo 37, §6으 da Constituição Federal de 1988 aponta que:
}

Art. $37 \S 6$ o As pessoas jurídicas de direito público e as de direito privado prestadoras de serviços públicos responderão pelos danos que seus agentes, nessa qualidade, causarem a terceiros, assegurado o direito de regresso contra o responsável nos casos de dolo ou culpa.

Interpretando tal dispositivo, o STF já firmou entendimento a partir de que tal disposição consagra uma espécie de dupla garantia, no sentido de proteger o lesado, que poderá demandar contra o Estado e o próprio agente público, o qual somente poderia ser demandado pelo respectivo ente em sede de ação regressiva, em casos de dolo ou culpa, como disposto no RE $327.904^{11}$. Tal precedente, no entanto: a) não é proveniente do plenário da Corte; b) não envolvia atuação do Ministério Público, distinção essencial no presente caso, como será pontuado em seguida.

Como dito, tal precedente é inaplicável ao presente caso em estudo, pois ele não versara sobre ação proposta pelo Ministério Público, mas sim por particular, distinção essencial ante a função institucional do Parquet na proteção ao patrimônio público e consequente responsabilização direta do agente, nos casos de dolo ou culpa. $O$ estudo da distinção ou mesmo do abandono de precedente equivocado merece ser efetivado no âmbito de uma teoria dos precedentes que privilegia a força hermenêutica deles.

Os precedentes judiciais têm ganhado relevância cada vez mais acentuada no sistema jurídico brasileiro, a ponto de o Código de Processo Civil (CPC) ter ampliado o rol de decisões judiciais capazes de demandar observância para os diversos órgãos do Poder Judiciário que estejam em posição de inferioridade em relação aos respectivos Tribunais que as tenham prolatado ${ }^{12}$. Além disso, o CPC estipula que é dever dos Tribunais manter sua jurisprudência íntegra, coerente e estável ${ }^{13}$, não, obviamente, imutável.

\footnotetext{
${ }^{11}$ Relator Ministro Carlos Britto.

${ }^{12}$ Art. 927. Os juízes e os tribunais observarão:

I - as decisões do Supremo Tribunal Federal em controle concentrado de constitucionalidade;

II - os enunciados de súmula vinculante;

III - os acórdãos em incidente de assunção de competência ou de resolução de demandas repetitivas e em julgamento de recursos extraordinário e especial repetitivos;

IV - os enunciados das súmulas do Supremo Tribunal Federal em matéria constitucional e do Superior Tribunal de Justiça em matéria infraconstitucional;

V - a orientação do plenário ou do órgão especial aos quais estiverem vinculados.

${ }^{13}$ Art. 926. Os tribunais devem uniformizar sua jurisprudência e mantê-la estável, íntegra e coerente.
} 
A fundamentação da decisão judicial como exercício de argumentação jurídica consistente no oferecimento de razões para justificar uma ação ${ }^{14}$ deve levar em conta os precedentes. No sistema jurídico brasileiro, isso é uma decorrência da própria lei, podendo a falta de cuidado no manejo dos precedentes acarretar a nulidade da decisão ${ }^{15}$.

Assim, a utilização prática do precedente envolve sempre a consideração de uma decisão anterior e outra atual. Além disso, a força dos precedentes varia conforme eles sejam analisados vertical ou horizontalmente: os precedentes verticais são aqueles normalmente mais fortes, eis que formados por uma corte superior para posterior observância por parte de uma corte inferior, enquanto os precedentes horizontais são aqueles da própria corte, variando sua força ou mesmo a existência de vinculação para casos futuros ${ }^{16}$.

Tal distinção, no entanto, não é suficiente para esgotar as considerações em torno da força dos precedentes, a qual é dependente de diversos outros fatores ${ }^{17}$, destacando-se, no que interessa mais de perto a esta pesquisa, a formação de um precedente que conceda claro privilégio ao agente público, o qual somente poderia ser demandado regressivamente. $O$ tema será retomado quando da análise dos requisitos para overruling, reconhecendo-se, desde já, que um precedente cuja ratio decidendi possa ser formulada como regra, apresenta uma força vinculante mais significativa do que precedentes mais amplos formulados como princípios ${ }^{18}$.

Diante da diç̧ão do art. 927 CPC, tem-se que diversas decisões de tribunais superiores apresentam força vinculante em relação aos órgãos inferiores do Poder Judiciário, sendo exemplo de precedentes verticais. No caso do STF e de seus próprios precedentes, deve-se relembrar que a Constituição, ao regulamentar o efeito vinculante, expressamente afasta sua

14 MACCORMICK, Neil. Argumentação jurídica e teoria do direito. Tradução de Waldéa Barcellos. São Paulo: Martins Fontes, 2009. p, 17.

${ }^{15}$ Art. 489 do CPC: São elementos essenciais da sentença:

§ 1ㅇNão se considera fundamentada qualquer decisão judicial, seja ela interlocutória, sentença ou acórdão, que: (...)

V - se limitar a invocar precedente ou enunciado de súmula, sem identificar seus fundamentos determinantes nem demonstrar que o caso sob julgamento se ajusta àqueles fundamentos;

VI - deixar de seguir enunciado de súmula, jurisprudência ou precedente invocado pela parte, sem demonstrar a existência de distinção no caso em julgamento ou a superação do entendimento.

${ }^{16}$ SCHAUER, Frederick. Thinking like a lawyer. Cambridge, Massachusetts: Harvard University Press, 2009. Kindle edition. posição 502-564.

17 Juraci Mourão elenca os diversos elementos formais de determinação da força hermenêutica do precedente, tais como a) nível hierárquico da corte emissora; b) tipo de processo em que se emitiu o precedente; c) órgão interno do tribunal emissor; d) votação por maioria ou unanimidade e e) modificação da composição da corte emissora, bem como os respectivos elementos materiais que determinam tal força: f) fundamentação adequada e detida; g) grau qualitativo e quantitativo de análise das questões de fato e de direito envolvidas; h) o ramo do direito envolvido; i) a idade do precedente; j) a observância da coerência; l) existência ou não de desafio ao precedente; $m$ ) similitude hermenêutica das questões suscitadas; n) guinada jurisprudencial e efeito ex tunc; o) observância de precedentes não judiciais; p) modificação o plano legislativo ou constitucional; q) modificação ou manutenção do quadro político e social geral; r) apoio ou desafio acadêmico. Dependendo da conjugação desses diversos fatores, ter-se-á uma condição mais facilitada ou dificultada para superação do precedente. LOPES FILHO, Juraci Mourão. Os precedentes judiciais no constitucionalismo brasileiro contemporâneo - 2ª edição. Salvador: Jus Podivm, 2016 p. 419-449.

18“Numa palavra, o maior grau de objetivação das normas jurídicas do tipo regra faz com que a vinculatividade das normas extraídas de precedentes judiciais varie não apenas em função da sua generalidade, mas também de sua estrutura stricto sensu. Portanto, vale a seguinte diretiva: normas jurisprudenciais do tipo "regra" têm um peso ou vinculatividade maior que as do tipo "princípios". BUSTAMANTE, Thomas. Teoria do precedente judicial. A justificação e a aplicação de regras jurisprudenciais. Noeses: São Paulo, 2012. p, 350, 352-353. 
A integridade do Direito e o dever de o Ministério Público processar diretamente o agente público: o caso dos danos morais coletivos praticados pelo Ministro da Educação

incidência ao próprio STF, eis que aponta a força de tais precedentes aos demais órgãos do Poder Judiciário.

A investigação acerca da integridade do Direito passa pela análise necessária da teoria da integridade de Ronald Dworkin. Este é o ponto de partida que se impõe não somente pela autoridade intelectual do autor, mas também porque, no Brasil, tal teoria jurídica influenciou fortemente a própria redação do art. 924 do CPC, como adiante será demonstrado. Logo, o direito brasileiro admite a superação dos precedentes, prática denominada overruling. A questão é identificar quando e como isso pode acontecer, compatibilizando a vinculação do stare decicis com o overruling, pois "sem uma consistente teoria do overruling, tem-se um paradoxo: uma corte suprema deve seguir seus precedentes mas, em qualquer caso, pode superá-los"19. A vagueza da norma legal aponta para requisitos com fundamentação específica e adequada, proscrevendo a simples omissão na análise dos precedentes: se eles existem, devem ser analisados e enfrentados, especialmente se o intuito for de superação.

Uma teoria acerca da possibilidade de superação dos precedentes quando estes, apesar de coerentes não são íntegros, não merecendo força gravitacional, é sustentada, por exemplo, por Dworkin, conforme abordado em seguida. Esta é uma das formas apontadas pela doutrina para superação de um precedente: correção de um erro cometido no passado. Evidentemente, o erro deve ser justificado com base em algum parâmetro. Para Dworkin, trata-se da ofensa ao direito como integridade.

O sistema jurídico nacional consignou, expressamente, que os Tribunais devem manter sua jurisprudência íntegra, coerente e estável. Há referência expressa à integridade, como dito, justificando todo o estudo teórico em seguida efetivado, despontando a teoria de Dworkin como a mais autorizada para a interpretação do dispositivo, como sustenta Lenio Streck:

A atenção que foi dispensada pelo atento relator na Câmara, Deputado Paulo Teixeira e o apoio inestimável de Fredie Didier e Luiz Henrique Volpe, foram cruciais para o acatamento da minha sugestão de que o NCPC passasse a exigir "coerência e integridade" da e na jurisprudência. Isto é: em casos semelhantes, deve-se proporcionar a garantia da isonômica aplicação principiológica. Trata-se da necessária superação de um modelo estrito de regras, sem cair no panprincipiologismo que tanto critico. Simples assim...e complexo.

\footnotetext{
${ }^{19}$ A questão não é simples, levando a doutrina a apontar um verdadeiro mistério em torno do tema: "Stare decisis-a court's duty to follow precedents - sometimes gives way to a court's power to overrule them. When this should happen, however, is a mystery. We need a sound theory of overruling to unravel the mystery. But we simply do not have one.

The challenge for such a theory is to resolve a conflict between stare decisis and overruling. Both are vital to the legal system. Stare decisis fosters unity, stability, and equality over time. Overruling enables supreme courts to correct their past errors and to adapt the law to changing circumstances. Without a sound theory of overruling, a paradox results: A supreme court must follow its precedents but, in any case, it can overrule them". BURTON, J. Steven. The conflict between stare decisis and overruling in constitutional adjudication. Cardozo law review. Vol. 35:1687, 2014. p, 1687-1688.
} 
Antes de "minha emenda", o projeto continha a obrigação de os tribunais manterem apenas a "estabilidade" da jurisprudência (art. 882 do PLS 166/2010). Dizia eu: " Não basta a estabilidade. Precisamos mais." E propus a emenda.

Assim, haverá coerência se os mesmos preceitos e princípios que foram aplicados nas decisões o forem para casos idênticos;

(...)

Já a integridade é duplamente composta, conforme Dworkin: um princípio legislativo, que pede aos legisladores que tentem tornar o conjunto de leis moralmente coerente, e um princípio jurisdicional, que demanda que a lei, tanto quanto possível, seja vista como coerente neste sentido. A integridade exige que os juízes construam seus argumentos de forma integrada ao conjunto do direito, constituindo uma garantia contra arbitrariedades interpretativas; coloca efetivos freios, através dessas comunidades de princípios, às atitudes solipsistasvoluntaristas ${ }^{20}$.

Ronald Dworkin notabilizou-se como um dos mais influentes filósofos do direito do século XX a partir de seu famoso ataque ao positivismo jurídico desenvolvido por Herbert Hart. Nessa linha, é relevante o estudo dos argumentos de princípio e política desenvolvidos por Dworkin, especialmente quando se constata que um precedente só teria força gravitacional, a saber, a possibilidade de exercer influência sobre casos futuros, se formado a partir de uma argumentação com base em princípios, não com base em política ${ }^{21}$. Como será demonstrado, a tese lançada no RE 327.904 apresenta-se como argumentação muito mais próxima da política, pois impõe, necessariamente, o custo a indenização à toda a coletividade, através dos recursos públicos do Estado, e não ao ofensor. A responsabilização direta deste, em casos de dolo ou culpa, seria a argumentação princiopiológica, por outro lado, pois decisões com base em princípios também conferem deveres às pessoas e não somente direitos.

Para Dworkin, o direito não é uma questão unicamente de regras, com supunha ser a tese desenvolvida por Hart, mas sim uma questão de princípio: levar o direito a sério é reconhecer que há padrões jurídicos para além das regras, compostos por princípios que devem ser considerados jurídicos. Esses princípios garantem que, em casos difíceis, os juízes decidam a questão controvertida sem criar novo direito e aplicá-lo retroativamente, a saber, sem qualquer exercício de um poder discricionário, admitido por positivistas como Hart, muito embora de maneira restrita aos casos em que há textura aberta e zona de penumbra na aplicação das normas jurídicas ${ }^{22}$.

Dois argumentos justificam essa preocupação com a criação judicial do direito e a arbitrariedade que ela encerraria: a) segurança jurídica; b) o respeito ao Estado de Direito. Através do argumento da segurança jurídica, argumenta-se que a admissão em torno da criação de novo direito quando do julgamento de um caso acarretaria insegurança às pessoas,

\footnotetext{
${ }^{20}$ STRECK, Lenio Luiz. O que é isto - a exigência de coerência e integridade no novo Código de Processo Civil? In. Hermenêutica e jurisprudência no novo Código de Processo Civil. Coerência e integridade. STRECK, Lenio Luiz; ALVIM, Eduardo Arruda; LEITE, George Salomão (orgs.). São Paulo: Saraiva, 2016. p, 157-158.

${ }^{21}$ DWORKIN, Ronald. Levando os Direitos a sério. Tradução de Nelson Boeira. São Paulo: Martins Fontes, 2010. p, 175-177.

${ }^{22}$ HART, Herbert L. A. O conceito de Direito. Tradução de Antônio de Oliveira Sette-Câmara. São Paulo: Martins Fontes, 2012. p, 161-176.
} 
A integridade do Direito e o dever de o Ministério Público processar diretamente o agente público: o caso dos danos morais coletivos praticados pelo Ministro da Educação

eis que não teriam como antever o surgimento de novas obrigações jurídicas. Em relação ao argumento do Estado de Direito, ataca-se a possibilidade de agentes oficiais não eleitos como os juízes inovarem na ordem jurídica sem legitimidade popular para tanto ${ }^{23}$. Dworkin acredita, assim, que lutar contra a discricionariedade judicial é garantir segurança e respeito à democracia.

Como fazer com que juízes decidam casos difíceis sem apelar para um poder discricionário, o qual atrairia as críticas elencadas no parágrafo anterior? A partir de uma argumentação baseada em princípios, não em políticas. Argumento de princípio é aquele que busca conferir algum direito individual ou a um grupo de pessoas. Argumento de política, por sua vez, é aquele que busca aumentar o bem estar coletivo, perseguindo alguma meta social e economicamente relevante ${ }^{24}$.

A garantia da presunção de inocência contra uma maioria que busca punição a qualquer custo é um exemplo de argumentação baseada em princípio ${ }^{25}$. A concessão de incentivos fiscais a certas empresas seria exemplo de prática baseada em argumentos de princípio. A argumentação por princípios teria como local mais adequado para desenvolvido o Poder Judiciário. A argumentação por política, o Poder Legislativo.

Não há como exigir coerência na política: uma lei que conceda incentivos fiscais a certo setor não pode ser utilizada por outro para pleitear a mesma política em seu favor. Considerações gerais econômicas acerca do bem estar podem justificar a oportunidade de tal discriminação. Nas Cortes a situação é diferente: estando em jogo um direito fundamental, uma decisão tomada com base em princípio merece ser seguida posteriormente pelos demais julgadores. Essa seria a consistência articulada do precedente: determinação de tratar os casos semelhantes de modo igual. A consistência articulada, por sua vez, só surgiria se o precedente tivesse força gravitacional, quando formado a partir de argumentos de princípio.

Argumentar com base em princípios, no entanto, é tarefa bastante complexa. Gradualmente, Dworkin vai desenvolver uma teoria capaz de justificar o direito a partir da atuação de um juiz que seria capaz de interpretar o direito na sua melhor luz, a quem denomina de Hércules. É a partir dele que o direito como integridade vai ser desenvolvido.

Direito como integridade parte da premissa de que direito não é somente aquilo prévia e expressamente posto nas convenções, como a lei, nem aquilo prospectivamente almejado pelo consequencialismo pragmático ${ }^{26}$. Quando o autor vai tratar do direito como integridade, por outro lado, ele inicia sua tese apontando a necessidade de as leis e não somente a decisão judicial, buscar o ideal de coerência. Ele critica, por exemplo, posturas do legislativo que buscam soluções de compromisso na elaboração das leis, tentando aprovar projetos de certo modo parciais: ao invés de conceder o exato direito que as pessoas

\footnotetext{
${ }^{23}$ DWORKIN, Ronald. Levando os Direitos a sério. Tradução de Nelson Boeira. São Paulo: Martins Fontes, 2010. p, 128-135.

${ }^{24}$ DWORKIN, Ronald. Levando os Direitos a sério. Tradução de Nelson Boeira. São Paulo: Martins Fontes, 2010. p, 128-132.

25 O exemplo é nosso, aproximando-se de outros trazidos por Dworkin no contexto dos direitos fundamentais do acusado no processo penal, referente a buscas domiciliares ilegais.

${ }^{26}$ DWORKIN, Ronald. O império do Direito. Tradução de Jefferson Luiz Camargo. São Paulo: Martins Fontes. p, 271.
} 
acreditam que possuem, adotam soluções intermediárias, conciliando com interesses contrapostos. Para Dworkin, tal prática viola a integridade ${ }^{27}$.

Direito é uma prática que busca identificar os princípios de moralidade política implícitos nas práticas sociais positivadas, princípios esses que estão na base da própria decisão dos membros de dada sociedade em assim viverem. O direito como integridade, assim, parte da premissa de que a sociedade organizou-se em bases fraternais, com cada membro demonstrando igual consideração e respeito aos demais ${ }^{28}$.

Cabe ao juiz Hércules, um ideal teórico desenvolvido por Dworkin, identificar esses princípios a partir da construção de uma teoria jurídica que melhor justifique a prática social em questão e sirva, ainda, como um precedente para os casos futuros. Como, na prática, não há juízes com o tempo e sabedoria necessários para serem tachados como Hércules, o que se deve buscar, segundo a teoria de Dworkin, é a maior aproximação possível com tal modelo ${ }^{29}$.

O direito como integridade é almejado por tal juiz, que não se contenta em somente tratar casos semelhantes de modo igual: esse seria o necessário conteúdo da coerência, mas incompleto. Necessário porque expressa uma concretização do princípio da igualdade. Incompleto porque, sem a devida atenção substancialista ou de conteúdo, poderia acarretar a igualdade entre os ilícitos, a saber, a coerência no erro. A integridade supera esses vícios, apontando que os precedentes merecem ser seguidos somente se justificarem uma decisão correta.

Veja-se o seguinte exemplo de Dworkin. Decisões judiciais que admitam a responsabilidade por negligência de diversos profissionais excluem a possibilidade de responsabilização dos advogados por fatos semelhantes. A coerência demandaria, assim, que um caso envolvendo responsabilidade de advogados fosse julgado improcedente. Afinal, os precedentes em casos semelhantes dispõem nesse sentido. Mas é correta a discriminação? Há fundamento jurídico para tanto? Essas são perguntas que vão além da mera coerência, perquirindo pela integridade do Direito: em não havendo justificativa, nada mais correto que abonar os precedentes que vedavam a responsabilização dos advogados, readequando-os à nova realidade ${ }^{30}$.

Em síntese, tem-se que: a) levar os direitos à sério determinada compreender o papel que os princípios jurídicos apresentam na argumentação; b) os casos difíceis devem ser decididos com base em princípios, não em política; c) os precedentes assim formados apresentam força gravitacional capaz de gerar uma consistência decisória articulada, a saber, demandando decisões íntegras; d) coerência não é mesmo que integridade; e) caberia a um juiz especialmente treinado construir uma teoria jurídica capaz de produzir decisões íntegras.

Feitas essas necessárias considerações, é possível sustentar a tese de que eventual decisão que afaste a responsabilização direta do Excelentíssimo Senhor Ministro da Educação

\footnotetext{
${ }^{27}$ DWORKIN, Ronald. O império do Direito. Tradução de Jefferson Luiz Camargo. São Paulo: Martins Fontes. p, 216-223.

${ }^{28}$ DWORKIN, Ronald. O império do Direito. Tradução de Jefferson Luiz Camargo. São Paulo: Martins Fontes. p, 251-259.

${ }^{29}$ DWORKIN, Ronald. O império do Direito. Tradução de Jefferson Luiz Camargo. São Paulo: Martins Fontes. p, 294.

${ }^{30}$ DWORKIN, Ronald. O império do Direito. Tradução de Jefferson Luiz Camargo. São Paulo: Martins Fontes. p, 264.
} 
não será íntegra, ofendendo o art. 926 do CPC, pois a decisão que transfere o custo da indenização do agente público para a própria sociedade, através da União, penalizando duplamente os próprios estudantes e professores lesados não é uma decisão tomada com base em princípio, mas sim em política, relacionada à mera conveniência do agente público em sentir-se livre de constrangimentos com o ajuizamento de ações de responsabilização. Isso não é garantir direitos, mas sim privilégios completamente incompatíveis com a integridade.

Desatentos ao uso dos precedentes a partir de uma teoria rigorosa, a União e o Ministro, ao apresentarem suas contestações na respectiva ação ${ }^{31}$, incidiram em equívocos ao propor a observância de precedentes inaplicáveis ao caso, não exercitando corretamente a distinção. A única questão preliminar elencada nas contestações da União e do Excelentíssimo Senhor Ministro da Educação refere-se à ilegitimidade passiva deste. Para fundamentar a tese, os demandados citam 8 ementas e um trecho do voto do Ministro Carlos Britto, do Supremo Tribunal Federal, supondo que tais julgados seriam aplicáveis ao presente caso, por consagrarem a tese da dupla garantia.

A questão processual, então, estava intimamente relacionada ao uso e interpretação dos precedentes. Nesse contexto, os réus cometeram pelo menos dois equívocos: a) tomam ementa como sinônimo de precedente; b) buscam aplicar as citadas ementas a um caso completamente diverso. Essas duas atecnias demonstram aplicação errônea da melhor teoria dos precedentes, como a desenvolvida no Brasil por Juraci Mourão Lopes Filho, já citado na introdução, sendo tal constatação inicial importante para que se conferir um menor peso argumentativo às teses defensivas.

À exceção de trecho do Voto do Ministro Ayres Britto, os réus elencaram diversas ementas nas respectivas contestações, como dito, entendendo que elas seriam aptas a fundamentar a respectiva tese acerca da ilegitimidade. Ocorre que precedente não se confunde com ementa, sendo está, unicamente, um resumo das principais teses elencadas na fundamentação da decisão, podendo, quando muito, ser apta a descortinar a ratio decidendi do julgado quando lida em conjunto com as razões elencadas nos respectivos votos. Quando citada sem esse cuidado, como ocorreu com pelo menos 7 das 8 ementas elencadas, tem-se um claro exemplo de vício no uso dos precedentes já apontando pela doutrina:

De fato, a ementa normalmente é estruturada em uma geral e curta descrição dos fatos da causa, seguida da enunciação do critério jurídico utilizado, nos moldes de um enunciado normativo, concluindo com a asserção de provimento ou improvimento do recurso. Também é bastante comum a simples enunciação do critério jurídico considerado pela Corte.

São típicas dos julgamentos colegiados, cuja obrigatoriedade é de leitura do voto integral pelo relator e sobre ele girar o julgamento. $\mathrm{O}$ voto, por sua vez, deve ser estruturado em relatório, fundamentação e dispositivo. Nele, deve haver a análise dos argumentos das partes e a plena exposição e julgamento das questões suscitadas e controvertidas. Eventual divergência deverá também ser exposta de maneira fundamentada e completa. Mesmo se manifestada oralmente, deverá ser reduzida a escrito posteriormente. Esse é o disciplinamento de um julgamento colegiado. Nada versa sobre

${ }^{31}$ Ação Civil Pública número 0800928-89.2019.4.05.8401. 10ạ Vara Federal da Subseção Judiciária de Mossoró. 
ementas, nem mesmo o modo de redigi-las. Surgiram como simples instrumento de catalogação para posterior consulta, não compondo o raciocínio decisório. ${ }^{32}$

(...)

É preciso, todavia, adiantar que um pronunciamento jurisdicional pode ser considerado em três aspectos: a) preceitos jurídicos enunciados nele, restringindo-se o uso posterior à sua aplicação descontextualizada; b) aspectos fáticos, autorizando as similitudes e divergências encontradas entre um caso e outro; e c) fundamentação e argumentação expedidas, a fim de reutilizá-las e reconstituí-las no caso posterior.

$\mathrm{O}$ adequado uso do precedente deve considerar necessariamente os três aspectos e outros elementos hermenêuticos, como será visto. Só assim é possível aferir a ratio decidendi em seu devido matiz dialético, apreendendo o jogo de perguntas e respostas do ciclo hermenêutico. De fato, a existência de todos esses elementos é que indica a importância dos precedentes no sistema jurídico, pois eles possuem o arcabouço hábil a determinar seu uso posterior, sendo justamente esta sua principal diferença para uma norma legislativa. Em se prestigiando um desses aspectos, em detrimento dos outros, há mera alusão superficial a um precedente e não verdadeiro e adequado uso.

Nesse sentido, o Código de Processo Civil de 2015 é bastante feliz ao dispor em seu art. 489, §1ำ V, que não se considerar fundamentada uma decisão, seja ela interlocutória, sentença ou acórdão, que "se limitar a invocar precedente ou enunciado de súmula, sem identificar seus fundamentos determinantes nem demonstrar que o caso sob julgamento se ajusta àqueles fundamentos". (sem destaques no original)

Há relevância prática no enfrentamento desse primeiro equívoco dos réus? Sim, não se está atacando um equívoco unicamente teórico, pois, ao não analisar detidamente os aspectos fáticos dos casos citados, tarefa impossível de se fazer unicamente com o manejo de ementas, como a citação acima demonstra, os réus acabaram por incidir no segundo equívoco adiante enfrentando, ao pretenderem aplicar precedentes relacionados a ações propostas por particulares $^{33}$ na ação ora em estudo, proposta pelo MPF.

\footnotetext{
${ }^{32}$ LOPES FILHO, Juraci Mourão. Os precedentes judiciais no constitucionalismo brasileiro contemporâneo - 2a edição, 2016, p. 105-107.

${ }^{33}$ As ementas citadas pelos réus comprovam a alegação: CONSTITUCIONAL. PROCESSUAL CIVIL. CIVIL. SINDICATO. LEGITIMIDADE ATIVA. ÓRGÃO MINISTERIAL. ILEGITIMIDADE PASSIVA AD CAUSAM. APELAÇÃO IMPROVIDA. 1. O entendimento jurisprudencial é no sentido de que os sindicatos, na condição de substitutos processuais, estão legitimados para postularem em juízo direitos da categoria, independentemente de autorização expressa dos substituídos ou juntada de relação nominal dos filiados (STJ, AGREsp n. 1028574, Rel. Min. Jorge Mussi, j. 04.06.09; (TRF da 3a Região, AMS n. 00111407420024036100, Rel. Des. Fed. Antonio Cedenho, j. 09.09.13; ApelReex n. 0020739082004036100, Rel. Des. Fed. Cecília Mello, j. 25.03.08). A matéria restou pacificada em sede de recurso extraordinário com repercussão geral (STF, RE n. 883642-RG, Rel. Min. Ricardo Lewandovski, j. 16.06.16). Registre-se que o RE n. 573.232 diz respeito às entidades associativas. 2. Assim, não prospera a alegação de ilegitimidade ativa do Sindicato, por ausência de autorização expressa dos substituídos para o ingresso em juízo. 3. O cerne do debate travado no presente processo, até o momento, diz respeito à existência ou não de legitimidade passiva do Procurador da República Marco Antônio Delfino de Almeida para integrar o polo passivo da ação. 4 . O requerido na presente ação agiu no legítimo espectro de suas
} 
A integridade do Direito e o dever de o Ministério Público processar diretamente o agente público: o caso dos danos morais coletivos praticados pelo Ministro da Educação

atribuições funcionais, zelando, ainda, pelos interesses das populações indígenas, também função institucional do Ministério Público Federal. 5. A solução albergada pela sentença recorrida, acostada às fls. 1808/1810v dos autos, é sem dúvida a que melhor preserva os interesses da atuação institucional do Ministério Público Federal, sem descurar dos interesses privados representados pelo autor; a que melhor, portanto, concilia e pondera os interesses em jogo. 6. Com efeito, a permitir-se o acionamento direto dos agentes públicos pelos particulares, a função pública resta imediatamente prejudicada, pois seus agentes poderão sentir-se intimidados no exercício de suas funções. As altas atribuições e missões conferidas ao Ministério Público Federal, desempenhadas com denodo pelos seus membros, inobstante a existência de erros e abusos, como em qualquer instituição humana, exigem para seu bom e frutífero desempenho que seus agentes estejam ao abrigo de perseguições descabidas e ameaças injustas. 7. A solução, pois, de sede constitucional, que prevê a responsabilização da pessoa jurídica à qual o agente esteja vinculado, é capaz de propiciar ao agente essa necessária proteção. A ação deve ser proposta em face da União Federal que, vislumbrando o dolo ou a culpa do agente público, pode mover a cabível ação regressiva. Portanto, como já dito, tal solução não descura nem do interesse público de preservar a tranquilidade e independência do agente público, nem do interesse particular em ver penalizado o agente público faltoso. (...).(Ap 00010025620134036005, DESEMBARGADOR FEDERAL PAULO FONTES, TRF3 - QUINTA TURMA, eDJF3 Judicial 1 DATA:28/11/2017 ..FONTE_REPUBLICACAO:.)

ADMINISTRATIVO. PEDIDO DE REFORMA SEM QUE TENHA HAVIDO SUCUMBÊNCIA. FALTA DE INTERESSE RECURSAL. RESPONSABILIDADE CIVIL DO ESTADO. DUPLA GARANTIA. ASSÉDIO MORAL. NÃO CONFIGURAÇÃO. DESCONTO DE VALORES EM FOLHA DE PAGAMENTO DE SERVIDOR PÚBLICO. OFENSA AO PRINCÍPIO DO CONTRADITÓRIO. BANCA EXAMINADORA QUE REAVALIOU CRITÉRIOS DE AVALIAÇÃO DE DOCENTE. AUTONOMIA UNIVERSITÁRIA. ATO NÃO REVESTIDO DE ILEGALIDADE. MÉRITO ADMINISTRATIVO. IMPOSSI-BILIDADE DE REVISÃO PELO PODER JUDICIÁRIO. ADOÇÃO DA TÉCNICA DE FUNDAMENTAÇÃO PER RELATIONEM. POSSIBILIDADE. REMESSA NECESSÁRIA E APELOS IMPROVIDOS. 1. Inexiste interesse recursal quando a sentença impugnada se posiciona no idêntico sentido da tese declinada no apelo. Precedente do Superior Tribunal de Justiça. 2. A responsabilidade civil do Estado, na esteira do art. 37, parágrafo 6으, da $\mathrm{CF} / 88$, consagra uma dupla garantia: aos indivíduos em geral, que terão seus danos reparados em caso de ofensa, e aos agentes públicos que, em decorrência de dano causado a particular no exercício da função pública, apenas poderão ser demandados pelo Estado em demanda autônoma, e não pela vítima .(...).(APELREEX 00047258120114058500, Desembargador Federal Raimundo Alves de Campos Jr., TRF5 - Terceira Turma, DJE - Data::05/02/2014 Página::219.)

APELAÇÃO CÍVEL. RESPONSABILIDADE CIVIL. UNIÃO. JULGAMENTO ANTECIPADO DA LIDE. FATOS INCONTROVERSOS. CERCEAMENTO DE DEFESA. INOCORRÊNCIA. ILEGITIMIDADE PASSIVA DE AGENTE PÚBLICO. AUSÊNCIA DE DIFERENCIAÇÃO DE CONDUTAS. TEORIA DA DUPLA GARANTIA. INEXISTÊNCIA DE JULGAMENTO EXTRA PETITA. MATÉRIA DE ORDEM PÚBLICA. NULIDADE REJEITADA. MILITAR. OMISSÃO NA APURAÇÃO DE CONDUTA INFRACIONAL. ADVERTÊNCIA INDEVIDAMENTE PROFERIDA. ATOS ILÍCITOS. INOCORRÊNCIA. DANOS MORAIS. NÃO CABIMENTO. SENTENÇA MANTIDA. I. Não havendo controvérsia acerca dos fatos narrados na petição inicial, eis que admitidos pelos réus, é plenamente cabível o julgamento antecipado do feito, nos moldes do preconizado pelo art. 330, I, CPC/73 (art. 335, I, CPC/2015), já que desnecessária a dilação probatória. Ademais, o magistrado é o destinatário das provas e, entendendo estar o feito suficientemente instruído, a ele incumbe proferir fundamentadamente sua decisão. Precedentes. II. Sendo a ilegitimidade passiva condição da ação, é matéria de ordem pública, podendo ser reconhecida de ofício pelo magistrado, não havendo que se falar em julgamento extra petita. III. Conforme entendimento do C. STF, o art. 37, § 6o, da Constituição Federal, ao prever a responsabilidade objetiva dos entes públicos por atos praticados por seus agentes, calcada no risco administrativo, adotou, também, a teoria da dupla garantia, segundo a qual se assegura ao administrado de ter ressarcidos seus prejuízos independentemente da comprovação de conduta culposa ou dolosa de servidores públicos e, por outro lado, garante-se ao agente estatal ser processado apenas e tão somente pelo ente estatal. Precedentes do STF. IV. Não havendo distinção entre a conduta imputada ao agente público e à Administração, impende a exclusão daquele do polo passivo da ação. V. Nos termos do art. 37, § 60 da Constituição Federal, a responsabilidade da Administração configura-se mediante a demonstração da prática de ato ilícito de agente público, dano e nexo de causalidade entre ambos. VI. Não age de maneira ilícita o militar que, ao ter conhecimento de conduta grave praticada por seu subordinado em âmbito privado, o chama em ambiente reservado, juntamente com seus superiores, a fim de orientá-lo acerca de seu comportamento no âmbito civil, a fim de não macule a imagem da corporação, nos termos dos artigos 23, 24, 28, 30 do Regulamento Interno e dos $\begin{array}{llllll}\text { Serviços } & \text { Gerais } & \text { Organização } & \text { Militar. } & \text { (...). } & \text { (AC }\end{array}$ 
Quando a ação fora proposta, houve grande receptividade por parte da comunidade acadêmica e do público em geral, com ampla repercussão na mídia. Parcela do MPF, no entanto, ofereceu forte reação em grupos de whats app, argumentando, por exemplo, que a não aplicação da tese da dupla garantia restringiria a atuação do agente público, temeroso em responder diretamente às ações. Apresentando nítida preocupação corporativa, os procuradores da República estavam temerosos acerca da receptividade de tal tese em relação a Deltan Dallagnol, o qual tornar-se-ia um alvo mais facilitado. Nenhuma palavra foi apresentada acerca da tese em si e da necessidade de procuradores da República buscarem a proteção do patrimônio público, demonstrando uma covarde despreocupação com a argumentação jurídica e, unicamente, com uma mesquinha busca e manutenção do poder.

O grupo em que tais críticas foram desferidas tinha o nome de "Valoriza MPF", contando, como visto, com uma pauta predominantemente corporativa e com membros francamente aliados a Olavo de Carvalho e a ideias pré-modernas em torno, por exemplo, do movimento "Escola sem Partido", já que muitos dos seus integrantes assinaram manifesto a favor de tal projeto de lei ${ }^{34}$. Mesmo assim, o símbolo de tal grupo era, surpreendentemente, a famosa pintura "A liberdade guiada pelo povo", de Eugène Delacroix. Isso bem demonstra o nível de obscurantismo intelectual de parte do MPF.

A argumentação em torno do risco na atuação do agente não consegue afastar a tese ora defendida neste texto. O particular não ostenta a função de proteção ao patrimônio público como se tem com o MPF. Sendo assim, o MPF, demonstrando o dolo ou culpa do agente público, tem o dever de acioná-lo diretamente. A alegação em torno do temor que se pode causar no agente público é descabida, pois o MPF deve agir com responsabilidade, instruindo adequadamente suas investigações e atuando de maneira extremamente técnica. Com essas garantias e responsabilidades, somente o gestor que pratica ato ilícito com dolo ou culpa merece se preocupar com a atuação ministerial.

\section{- CONCLUSÕES}

O direito como integridade é capaz de fornecer uma resposta à utilização dos precedentes, buscando, para além da coerência, a correção dos pronunciamentos judiciais. Assim, o precedente que exprima uma decisão correta merecer ser seguido posteriormente, possuindo força gravitacional para tanto. Evidentemente, o critério acerca da correção será disputado, mas, em não se aderindo ao ceticismo em matéria ética, como não se aderiu no presente texto, é plenamente possível sustentar a falsidade e verdade das proposições jurídicas, a partir da teoria de Dworkin adotada neste texto. O direito como integridade é capaz de fornecer tal análise, sendo essencial seu estudo no contexto dos precedentes a partir da própria positivação da lei processual no Brasil.

Uma leitura do art. 37, §6o da Constituição que admita uma obrigatoriedade de demanda contra a pessoa jurídica não consagra um direito ou uma "dupla garantia" ao agente

https://arquivo.trf1.jus.br/PesquisaMenuArquivo.asp?p1=00028085320054013810, JUÍZA FEDERAL HIND GHASSAN KAYATH (CONV.), TRF1 - SEXTA TURMA, e-DJF1 DATA:17/02/2017 PAGINA:.) (sem destaques no original)

34 Disponível em: https://www.conjur.com.br/dl/nota-tecnica-copia-parecer-escola.pdf. Acessado em: 02/09/2019. 
público. Ela é mais compatível, na verdade, com um indisfarçável privilégio, pois, em momento algum, o dispositivo veda o ajuizamento direto de ação contra o respectivo agente. Há riscos em tal operação, relacionados, por exemplo, à solvabilidade daquele, mas quem deve fazer tal análise é o autor da ação, o qual pode ter interesse em não aguardar o pagamento de precatórios.

Se assim é em relação ao particular, há ainda mais razões para sustentar a tese quando se trata do Ministério Público. É dever funcional de tal instituição responsabilizar diretamente agente público que tenha praticado ato ilícito doloso ou culposo, pois assim estará conferindo máxima eficácia à norma constitucional que preconiza a proteção ministerial ao patrimônio público. O precedente firmado em sentido oposto e analisado no texto merecer ser afastado, pois não diz respeito à atuação ministerial, mas sim aos particulares, os quais não ostentam um dever na proteção do patrimônio público no sentido institucional que cabe ao Ministério Público.

\section{REFERÊNCIAS}

BURTON, J. Steven. The conflict between stare decisis and overruling in constitutional adjudication. Cardozo law review. Vol. 35:1687, 2014.

BUSTAMANTE, Thomas. Teoria do precedente judicial. A justificação e a aplicação de regras jurisprudenciais. Noeses: São Paulo, 2012.

DWORKIN, Ronald. Levando os Direitos a sério. Tradução de Nelson Boeira. São Paulo: Martins Fontes, 2010.

DWORKIN, Ronald. O império do Direito. Tradução de Jefferson Luiz Camargo. São Paulo: Martins Fontes.

HART, H.L.A. O conceito de Direito. Trad. de Antônio de Oliveira Sette-Câmara. São Paulo: Martins Fontes, 2012.

LOPES FILHO, Juraci Mourão. Os precedentes judiciais no constitucionalismo brasileiro contemporâneo - 2a edição. Salvador: Jus Podivm, 2016.

NINO, Carlos Santiago. Introdução à análise do Direito. Trad. Elza Maria Gasparotto. São Paulo: Martins Fontes, 2015.

RAMOS, Luaciana de Oliveira. SCHORSCHER, Vivian Cristina. Método do caso. In.: In.: Métodos de ensino em Direito - conceitos para um debate. GHIRARDI, José Garcez (org.). São Paulo: Saraiva, 2009.

SCHAUER, Frederick. Thinking like a lawyer. Cambridge, Massachusetts: Harvard University Press, 2009. Kindle edition.

STRECK, Lenio Luiz. O que é isto - a exigência de coerência e integridade no novo Código de Processo Civil? In. Hermenêutica e jurisprudência no novo Código de Processo Civil. Coerência 
e integridade. STRECK, Lenio Luiz; ALVIM, Eduardo Arruda; LEITE, George Salomão (orgs.). São Paulo: Saraiva, 2016. 